\title{
ASSESSMENT OF THE REGENERATION CAPACITY OF SEMITENDINOSUS AND GRACILIS TENDONS
}

\section{REGENERAÇÃO DOS TENDÕES DOS MÚSCULOS SEMITENDÍNIO E GRÁCIL APOS RETIRADA}

\author{
Leonardo José Bernades Albertoni ${ }^{1}$, Pedro Debieux ${ }^{1,3}$, Carlos Eduardo da Silveira Franciozi ${ }^{1,3}$, João Victor Novaretti ${ }^{2}$, \\ Geraldo Sergio de Melo Granata $J^{1}{ }^{1}$, Marcus Vinicius Malheiros Luzo ${ }^{1}$
}

1. Knee Surgery and Arthroscopy Group, Universidade Federal de São Paulo (UNIFESP-EPM), São Paulo, SP. Brazil. 2. Sports Traumatology Group, Universidade Federal de São Paulo (UNIFESP-EPM), São Paulo, SP, Brazil.

3. Hospital Israelita Albert Einstein, São Paulo, SP, Brazil.

\section{ABSTRACT}

Objectives: To evaluate the regenerative capacity of gracilis $(\mathrm{G})$ and semitendinosus (ST) tendons, to examine the sensitivity and specificity of signs and symptoms in the assessment of hamstring tendons, and to assess the thickness and insertion site of regenerated tendons. Methods: Thirty sequential knees were subjected to anterior cruciate ligament reconstruction with semitendinosus and gracilis tendons. After surgery, the patients were followed up clinically with physical examination and magnetic resonance imaging (MRI). Results: Overall, $36.66 \%$ of the tendons were visible on MRI, whereas $83.33 \%$ were palpable. On MRI, the distal insertion site of the regenerated semitendinosus tendon was visible proximal to the landmark of the medial femoral condyle in $28 \%$, at the same level in $16 \%$, and distally in $56 \%$ of the cases. Gracilis tendon insertion was visible proximally in $36.66 \%$ of cases, at the same level in $10 \%$, and distally in 53.33\%. Eleven knees exhibited complete regeneration. Conclusion: Partial or total regeneration of the ST and G tendons was apparent on MRI. Palpation is effective for evaluating regeneration of the ST and G tendons; however, MRI is still the gold standard. ST and $\mathrm{G}$ tendons regenerated completely in only a small percentage of patients, limiting reuse as a graft in cases with new ligament injuries of the knee. Level of Evidence II, Prospective comparative study.

Keywords: Knee, Tendons, Magnetic Resonance Imaging, Physical Examination.

\section{RESUMO}

Objetivo: Avaliar a capacidade de regeneração dos tendões Grácil e Semitendíneo; Identificar a sensibilidade e especificidade da manobra semiológica para detecção da presença dos tendões isquiotibiais; verificar espessura e região de inserção dos tendões regenerados. Métodos: 30 pacientes foram submetidos à cirurgia para reconstrução do LCA, com retirada dos tendões do semitendíneo e grácil. Após a cirurgia, os pacientes foram acompanhados clinicamente por exame físico e por RM. Resultados: Observou-se que em 36,66\% eles se apresentavam visíveis, enquanto $83,33 \%$ os tendões estavam palpáveis. Observou-se à $R M$, quanto a região da inserção distal dos tendões regenerados: Semitendíneos, 28\% proximal ao ponto padronizado do MFC, $16 \%$ se apresentaram ao nível e $56 \%$ distal. Já quanto aos tendões do Grácil, 36,66\% apresentavam-se proximais, 10\% ao nível e 53,33\% distal. Onze tendões do ST e do G tiveram regeneração completa. Conclusões: Ficaram caracterizadas, por RM, as regenerações parciais ou totais dos tendões ST e G;a palpação, é eficaz para avaliar a regeneração dos tendões, porém RM mantem-se como padrão ouro; apenas parte dos pacientes os tendões ST e G se regeneraram de maneira completa, limitando a sua reutilização como enxerto nos casos de nova lesão ligamentar. Nível de Evidência II, Estudo prospectivo comparativo.

Descritores: Joelho. Tendões. Ressonância Magnética. Exame Físico.

Citation: Albertoni LJB, Debieux P, Franciozi CES, Novaretti JV, Granata Jr GSM, Luzo MVM. Assessment of the regeneration capacity of semitendinosus and gracilis tendons. Acta Ortop Bras. [online]. 2018;26(6):379-83. Available from URL: http://www.scielo.br/aob.

\section{INTRODUCTION}

Knee ligament reconstruction is a common procedure. ${ }^{1}$ In general, a graft is placed in the position of the original ligament and assumes its function. Among the potential grafts available, there has been an exponential increase in the use of semitendinosus (ST) and gracilis (G) tendons in recent decades because of lower morbidity at the donor site, greater technical ease in removal, and the potential for accelerated recovery with decreased pain compared to that with other grafts. These features enable earlier rehabilitation without substantial loss of resistance, as these tendons produce similar or better results, with stretching characteristics comparable to those of other grafts. ${ }^{2-4}$

The versatility of this type of graft has also allowed the development of reconstruction techniques for practically all ligaments of the

All authors declare no potential conflict of interest related to this article.

Study conducted at the Universidade Federal de São Paulo (UNIFESP-EPM), São Paulo, SP, Brazil.

Correspondence: Pedro Debieux. Rua Borges Lagoa, 783, 5 andar, São Paulo, SP, Brasil. CEP 04038-030. E-mail pedrod.ortop@gmail.com 
knee using these tendons, in addition to ligament and tendon reconstructions extrinsic to the joint.

This scenario underlines the importance of evaluating the regenerative capacity of the hamstring tendons, as these are associated with the return of knee flexion strength. ${ }^{1,5}$ In 1992, Cross et al., ${ }^{6}$ using magnetic resonance imaging (MRI) in 4 patients, demonstrated that these tendons present substantial regenerative potential. Since then, several authors have studied this potential from a macroscopic $\mathrm{c}^{7-10}$ as well as histological standpoint. ${ }^{11,12}$ However, the literature on the regenerative capacity of the tendon, as well as its consistency and thickness, is unclear. Moreover, the new insertion site shows some variability. ${ }^{1,3,4,8}$ In this context, there is ample evidence in the literature indicating that tendons and ligaments are generally able to heal intrinsically. ${ }^{9,10}$ The mechanisms involved in regeneration, according to Eriksson et al., can be both intrinsic and extrinsic in origin. ${ }^{8}$ Extrinsic healing involves regeneration from the peritendinous tissue, with gradual invasion of capillaries and formation of granulation tissue. Intrinsic healing involves regeneration originating from the two ends of a cut tendon, without formation of granulation tissue or vascular invasion of peritendinous tissue. ${ }^{8}$

As the capacity for regeneration and the location of neotendinous insertion of the hamstrings remain controversial, the objectives of the present study were: (1) to assess the regenerative capacity of tendons at the graft donor site in patients undergoing anterior cruciate ligament $(\mathrm{ACL})$ reconstruction with ST and $\mathrm{G}$ tendons, (2) to determine the sensitivity and specificity of signs and symptoms in the assessment of these tendons, and (3) to assess the thickness and insertion site of regenerated tendons.

\section{MATERIALS AND METHODS}

After approval by the ethics committee, 29 sequential patients (30 knees) were selected based on the following inclusion criteria: isolated lesions with a surgical indication, absence of ligament injuries or previous knee surgery, absence of metallic materials in the knee or thigh (incompatible with MRI), no history of lower limb muscle injury, no limitation in range of motion, consent to participation in the rehabilitation protocol, commitment to outpatient follow-up, and signing of an informed consent form. The exclusion criteria were: ligament injuries or previous knee surgery, presence of metallic materials in the knee or thigh, history of muscle injury in the lower limb, or inability to participate in the rehabilitation protocol or outpatient follow-up. Each patient underwent surgery for ACL reconstruction using the same technique (isometric reconstruction) and fixation (bioabsorbable screws), and ST and G tendons were completely removed from the muscles up to the myotendinous junction in all cases. After surgery, patients were clinically followed-up with physical examination and MRI.

\section{Physical examination}

Physical examination to evaluate regeneration of the ST and G tendons was performed in accordance with the technique described by Cross et al. ${ }^{6}$ In the ventral decubitus position, the patient performed knee flexion against resistance, in order to demonstrate the presence or absence of the regenerated tendon in the posterior medial aspect of the knee. ${ }^{6}$ The examiner proceeded with inspection, followed by palpation of the region (Figure 1). Following physical examination, the patient was referred for MRI directly, so that both could be performed on the same day.

\section{Magnetic Resonance Imaging}

The results of these examinations were evaluated by two experienced radiologists who were specialists in musculoskeletal imaging. Discrepancies between the radiologists were resolved by consensus,

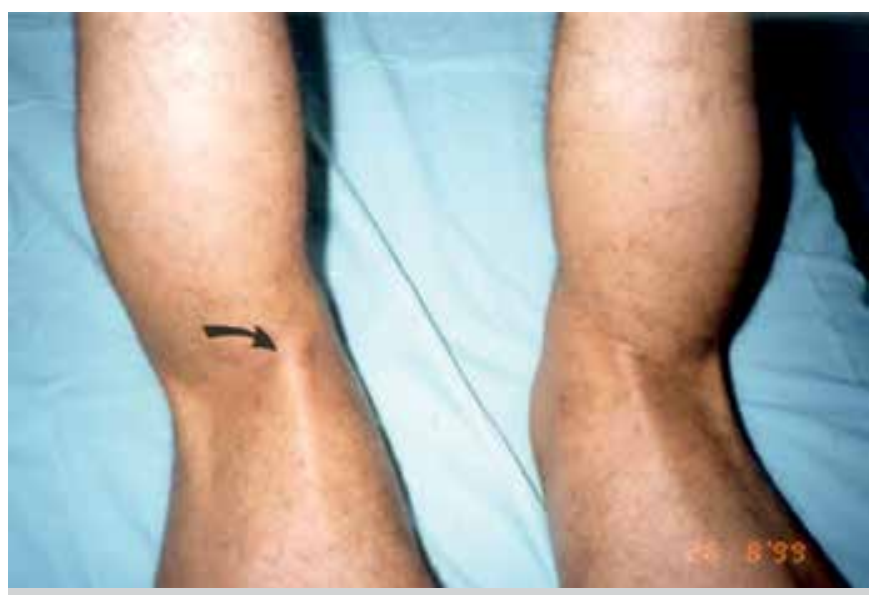

Figure 1. Visualization of the semitendinosus and/or gracilis tendons on physical examination, with knee flexion against resistance. Arrow: Regenerated tendons in the posterior medial aspect of the knee.

without the requirement for a third evaluator. The radiologists were informed that the tendons had been removed but were unaware of the interval between removal of the graft and the MRI examination. The MRI was performed on the segment of the lower limb between the middle third of the thigh and the proximal third of the leg. A Philips model NT 10 instrument, operating at a high magnetic field was used. A quadrature surface coil array was used to image the L-spine, which allowed simultaneous acquisitions with a $400-\mathrm{mm}$ field of view. The T1-weighted turbo spin echo technique was used with a repetition time of $550 \mathrm{~ms}$ and echo time of $12 \mathrm{~ms}$.

The images were obtained in coronal (Figures 2 and 3 ) and transverse planes (Figure 4), with a slice thickness of $5 \mathrm{~mm}$ and no gaps. We used the following to classify tendon regeneration based on location: $\mathrm{P}$, proximal to the most distal point of the medial femoral condyle (MFC) surface; N, at the most distal point of the surface of the MFC; $\mathrm{D}$, distal to the most distal point of the joint surface of the MFC; C, complete regeneration (up to the insertion point of the pes anserinus).

\section{Statistics}

The confidence interval $(\mathrm{Cl})$ and sampling error were calculated using the MRI values obtained from evidence of regeneration of the ST and G tendons. The sensitivity (S), specificity (E), positive predictive value (PPV), and negative predictive value (NPV), with their respective $95 \% \mathrm{Cls}$, were calculated for statistical comparison of the ability of physical examination and MRI evaluation to demonstrate ST and $\mathrm{G}$ tendon regeneration. There is no consensus on the gold standard for the evaluation of ST and G tendon regeneration. In this study, MRI examination was considered the gold standard.

\section{RESULTS}

Thirty knees (18 right, 12 left) of 29 adult patients (26 men) submitted to $A C L$ reconstruction with quadruple autografts of ST and/or G tendons were evaluated in this study. One patient underwent surgery on both knees, but at different time points. Patient ages ranged from 19 to 49 years (mean, 32 years). The average interval between surgery and the date of MRI and physical examination (performed on the same day) was 17 months (range: 9 to 34 months).

\section{Magnetic Resonance Imaging}

MRI examination of the knee was performed to assess the regenerative capacity of the ST and G tendons, but the current status of the tendon grafts in the knees of these patients was also analyzed. 


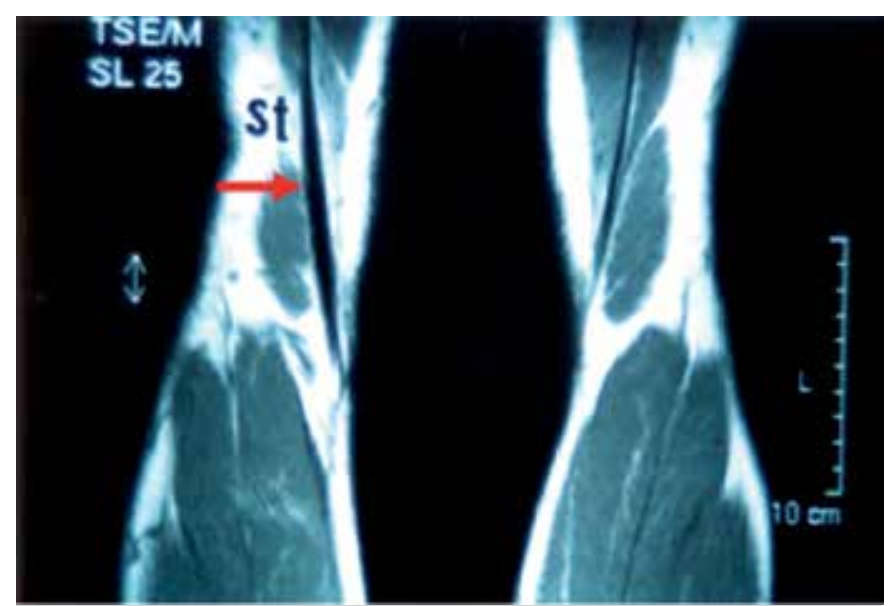

Figure 2. Magnetic resonance image of the knee: coronal section. Turbo spin-echo sequence: T1-weighted. Arrow: Regenerated semitendinosus tendon.

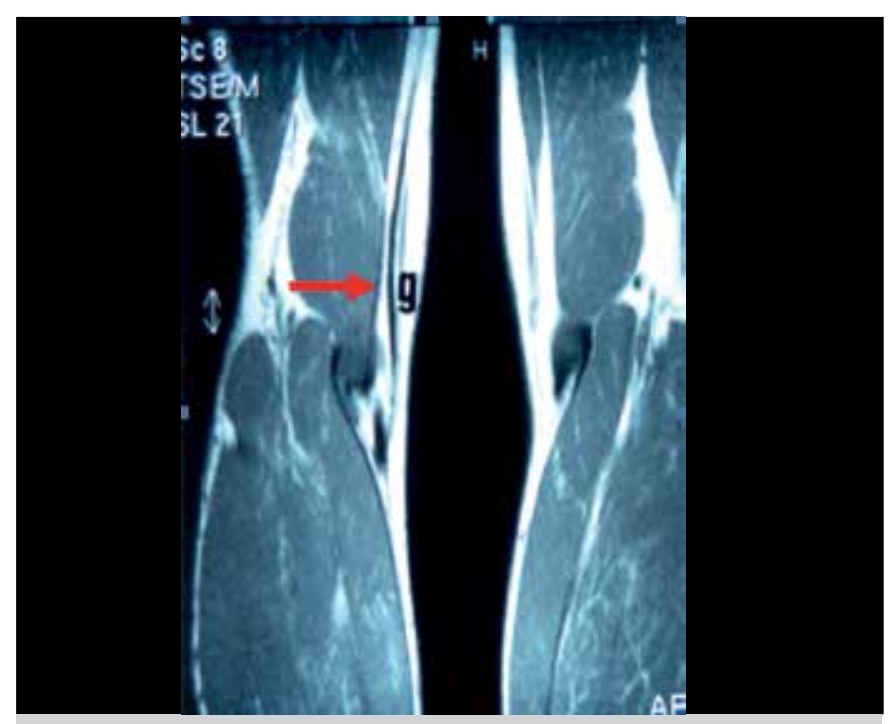

Figure 3. Magnetic resonance image of the knee: coronal section. Turbo spin-echo sequence: T1-weighted. Arrow: Regenerated gracilis tendon (g).

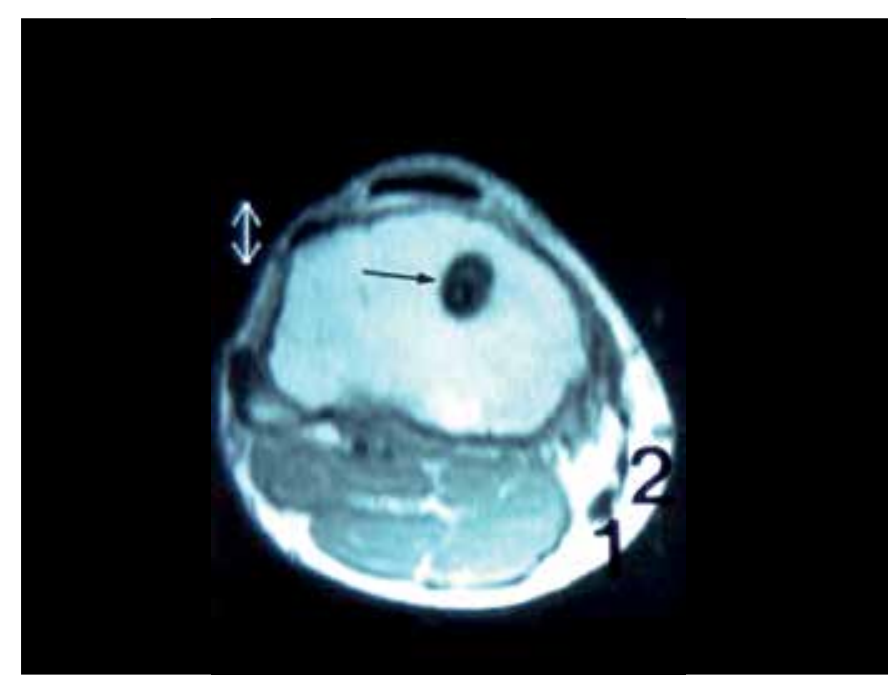

Figure 4. Magnetic resonance image of the knee: coronal section. Turbo spin-echo sequence: T1-weighted. Arrow: Regenerated gracilis tendon (g).
Transverse MRI images enabled location of the distal ends of the regenerated tendons with greater precision and were used to define their position with respect to the most distal point on the articular surface of the MFC.

Table 1 shows that 25 (83.33\%) of the ST tendons and 30 (100\%) of the $\mathrm{G}$ tendons were visualized with $\mathrm{MRI}$, demonstrating regeneration. With regard to the region distal to the insertion of the regenerated tendons, it was found that among 25 ST tendons, 7 (28\%) had their most distal portion proximal $(P)$ to the standard point of the MFC, 4 16\%) were at the same level (N), and 14 (56\%) were distal (D) to the standard point. Regarding the $\mathrm{G}$ tendons, of the 30 $(100 \%)$ that showed regeneration, $11(36.66 \%)$ were proximal $(P)$ to the standard MFC point, $3(10 \%)$ were at the same level $(\mathrm{N})$, and 16 (53.33\%) were distal (D). Eleven ST and G (36.66\%) tendons had their distal extent identified in the pes anserinus region, thus indicating complete regeneration.

Therefore, it can be inferred that significant regeneration occurred in both tendons. For ST tendons, the regeneration rate was $83.33 \%$. Considering sample variability, the estimated proportion showing tendon regeneration in the population was $0.833 \pm 0.134(95 \% \mathrm{Cl}$ $0.699-0.967$, with sampling error $=0.134)$. For $G$ tendons, the regeneration rate was $100 \%$ and $\mathrm{Cls}$ could not be calculated.

\section{Physical examination}

Regarding the visibility of tendons following the Cross maneuver ${ }^{8}$, 11 cases (36.66\%) were visible, whereas 19 (63.33\%) could not be visualized (Table 2). In contrast, on palpation, among the 30 knees evaluated, the ST and/or G tendons were palpable in 25 (83.33\%), while in 5 cases (16.66\%), palpation was not possible.

Inspection and palpation were more reliable than MRI. Thus, on palpation (Table 3) we observed the following: $S=0.96(95 \%$ $\mathrm{Cl} 0.805-0.993), \mathrm{E}=0.80(95 \% \mathrm{Cl} 0.376-0.964), \mathrm{PPV}=0.960$ (95\% Cl 0.805-0.993), NPV $=0.80$ (95\% Cl 0.376-0.964). On inspection, the values were (Table 4) $\mathrm{S}=0.44$ (95\% Cl 0.267-0.629), $E=1(\mathrm{Cl} 0.566-1.000), P P V=1(95 \% \mathrm{Cl} 0.741-1.000), \mathrm{NPV}=0.263$ (95\% Cl 0.118-0.488).

\section{DISCUSSION}

The first study on regeneration of the ST and G tendons was carried out by Cross et al., ${ }^{6}$ who used MRI in 4 patients to show that tendons showed increased regenerative potential. In 1997, Simonian et al. described the same phenomenon using MRI in 9 patients; on the basis of their results, they suggested tendon reuse in new ACL lesions. ${ }^{2}$ In the present study, the regeneration of the ST tendon was demonstrated by MRI examination in $83.33 \%$ of cases and that of

Table 1. Characterization of the semitendinosus and/or gracilis muscle tendons on physical examination stratified according to whether they were palpable and/or visible.

\begin{tabular}{c|c|c|c}
\hline Tendons & Yes & No & Total \\
\hline Palpable & 25 & 5 & 30 \\
\hline Visible & 11 & 19 & 30 \\
\hline
\end{tabular}

Table 2. Characterization of the semitendinosus (ST) and gracilis (G) tendons using $\mathrm{MRI}$, and the anatomical relationship between the most distal point of the joint and the medial femoral condyle.

\begin{tabular}{c|c|c|c|c|c|c}
\hline Tendons & P & N & D & C & Total & NI \\
\hline ST & 7 & 4 & 3 & 11 & 25 & 5 \\
\hline G & 11 & 3 & 5 & 11 & 30 & - \\
\hline Total & 18 & 7 & 8 & 22 & 55 & 5 \\
\hline
\end{tabular}

P: proximal, $\mathrm{N}$ : at the same level, D: distal, C: complete regeneration (up to the pes anserinus), $\mathrm{NI}$ : not identified. 
Table 3. Comparison of data obtained using clinical evaluation and MRI.

\begin{tabular}{|c|c|c|c|c|c|c|}
\hline № & $\begin{array}{c}\begin{array}{c}\text { Age } \\
\text { (years) }\end{array} \\
\end{array}$ & $\begin{array}{c}\text { ISE } \\
\text { (months) }\end{array}$ & $\mathbf{P}$ & V & ST & G \\
\hline 1 & 25 & 34 & $Y$ & $Y$ & $C$ & C \\
\hline 2 & 40 & 31 & $\mathrm{~N}$ & $\mathrm{~N}$ & $\mathrm{Nl}$ & $\mathrm{P}$ \\
\hline 3 & 23 & 24 & $Y$ & $Y$ & $C$ & $C$ \\
\hline 4 & 34 & 24 & $Y$ & $\mathrm{~N}$ & $\mathrm{~N}$ & $\mathrm{~N}$ \\
\hline 5 & 32 & 23 & $Y$ & $Y$ & C & $C$ \\
\hline 6 & 42 & 23 & $Y$ & $Y$ & $C$ & $\mathrm{C}$ \\
\hline 7 & 39 & 23 & $Y$ & $\mathrm{~N}$ & $C$ & $C$ \\
\hline 8 & 33 & 22 & $Y$ & $Y$ & $C$ & $C$ \\
\hline 9 & 42 & 21 & $Y$ & $\mathrm{~N}$ & $\mathrm{NI}$ & $D$ \\
\hline 10 & 29 & 20 & $\mathrm{~N}$ & $\mathrm{~N}$ & $\mathrm{NI}$ & $P$ \\
\hline 11 & 30 & 17 & $Y$ & $\mathrm{~N}$ & $\mathrm{~N}$ & $\mathrm{~N}$ \\
\hline 12 & 42 & 16 & $Y$ & $Y$ & $C$ & $C$ \\
\hline 13 & 31 & 16 & $Y$ & $Y$ & $C$ & $C$ \\
\hline 14 & 35 & 15 & $Y$ & $Y$ & $D$ & $P$ \\
\hline 15 & 31 & 15 & $\mathrm{~N}$ & $\mathrm{~N}$ & $\mathrm{NI}$ & $P$ \\
\hline 16 & 37 & 15 & $Y$ & $\mathrm{~N}$ & $\mathrm{~N}$ & $D$ \\
\hline 17 & 28 & 14 & $Y$ & $Y$ & $C$ & $C$ \\
\hline 18 & 36 & 14 & $\mathrm{~N}$ & $\mathrm{~N}$ & $\mathrm{NI}$ & $P$ \\
\hline 19 & 19 & 13 & $Y$ & $\mathrm{~N}$ & $\mathrm{P}$ & $P$ \\
\hline 20 & 23 & 13 & $Y$ & $\mathrm{~N}$ & $\mathrm{~N}$ & $\mathrm{~N}$ \\
\hline 21 & 25 & 13 & $Y$ & $\mathrm{~N}$ & $\mathrm{D}$ & $P$ \\
\hline 22 & 36 & 13 & $Y$ & $Y$ & $\mathrm{D}$ & $D$ \\
\hline 23 & 31 & 12 & $Y$ & $\mathrm{~N}$ & $C$ & $C$ \\
\hline 24 & 31 & 12 & $Y$ & $\mathrm{~N}$ & $\mathrm{P}$ & $P$ \\
\hline 25 & 27 & 11 & $Y$ & $\mathrm{~N}$ & $P$ & $D$ \\
\hline 26 & 39 & 11 & $Y$ & $\mathrm{~N}$ & $P$ & $D$ \\
\hline 27 & 25 & 10 & $Y$ & $\mathrm{~N}$ & $\mathrm{P}$ & $P$ \\
\hline 28 & 49 & 10 & $Y$ & $\mathrm{~N}$ & $P$ & $P$ \\
\hline 29 & 33 & 10 & $\mathrm{~N}$ & $\mathrm{~N}$ & $\mathrm{P}$ & $\mathrm{P}$ \\
\hline 30 & 29 & 9 & $Y$ & $Y$ & $C$ & $C$ \\
\hline
\end{tabular}

Patient Number $\left(\mathrm{N}^{\circ}\right)$, age, and interval between the date of surgery and the date of physical and MRI exams (ISE). Columns 3 and 4 characterize semitendinosus (ST) and/or gracilis (G) tendons based on physical examination, i.e., presence of palpable $(\mathrm{P})$ and/or visible $(\mathrm{V})$ tendons. Y: yes, $\mathrm{N}:=$ no. Columns 5 and 6 characterize the ST and $\mathrm{G}$ tendons using MRI and their anatomical relationships with the most distal point of the joint end of the medial femoral condyle. $\mathrm{P}$. proximal: $\mathrm{N}$ $=$ at the same level; D: distal; C: complete regeneration (up to the pes anserinus); $\mathrm{NI}=$ not identified.

Table 4. Comparison of palpation and magnetic resonance imaging (MRI) findings in determining regeneration of semitendinosus and/or gracilis tendons.

\begin{tabular}{|c|c|c|c|c|}
\hline \multirow{2}{*}{\multicolumn{2}{|c|}{ Yes }} & \multicolumn{3}{|c|}{ MRI } \\
\hline & & \multirow{2}{*}{$\begin{array}{l}\text { No } \\
24\end{array}$} & \multirow{2}{*}{$\frac{\text { Total }}{1}$} & \multirow[b]{2}{*}{25} \\
\hline \multirow{3}{*}{ Palpation } & Yes & & & \\
\hline & No & 1 & 4 & 5 \\
\hline & Total & 25 & 5 & 30 \\
\hline
\end{tabular}

the $\mathrm{G}$ tendon in $100 \%$ of cases. Only $36.66 \%$ of patients, however, displayed complete regeneration of the tendons. Comparing our results with published data, we observed that Zaccherotti et al. found regeneration of ST tendons in $70 \%$ of patients at 7 months postoperatively. ${ }^{12}$ Suijkerbuijk et al. analyzed 18 studies in a systematic review and concluded that there was, in fact, tendon regeneration, but that the strength and mechanisms facilitating this regeneration remain uncertain. ${ }^{13}$ These results were supported by Papalia et al., in a meta-analysis of 19 studies including approximately 400 individuals. ${ }^{14}$ Thus, the results of the above studies regarding the prevalence of regeneration supports the results of the present study, independent of the methods and protocols used for imaging tests and follow-up time, which makes our conclusions more precise than those of previous studies.

Papandrea et al. identified complete regeneration only if present at 18 months postoperatively, ${ }^{9}$ whereas Eriksson et al. identified complete regeneration in patients evaluated between 6 and 12 months postoperatively. ${ }^{8}$ In the present study, the complete regeneration of these tendons was more frequently found after a 1 -year interval after surgery and the date of MRI evaluation. We analyzed 6 patients with an interval of less than 1 year (ranging from 9 to 11 months). Of these, only 1 patient (16.66\%) presented complete regeneration of the tendons (Table 5). The remaining 24 had a postoperative period of greater than 1 year (ranging from 12 to 34 months) and 10 of these (41.66\%) presented complete tendon regeneration (Table 5).

The results obtained in this study, however, lead us to assume that we cannot rely on the reuse of these tendons for a new ACL lesion within this time interval, given that only a small portion of cases showed complete regeneration (only $36.66 \%$ reached the region of the hamstring anatomical insertion).

In terms of physical examination, firm structures similar to tendinous fibers were observed in the region that previously contained the tendons used as grafts. These structures were sometimes clearly visible; however, most times, they were only palpable due to the presence of abundant adipose tissue in the region. However, we observed during our study that when these tendons were clearly palpable and visible, they appeared regenerated on MRI examination. This was clearly demonstrated when comparing the physical examination results with those obtained by MRI examination using statistical analysis (Tables 4 and 5). When comparing palpation to MRI, we found high values for sensitivity, specificity, PPV, and NPV, which are signs that palpation is quite efficient in evaluating the regeneration of ST and $\mathrm{G}$ tendons (misinterpretation occurred in only 2 cases). When comparing inspection (visualization) to MRI, there was low sensitivity (sensitivity $=0.440$, with a $95 \% \mathrm{Cl} 0.267-0.629$ ), which means that inspection is not a reliable test to evaluate the regeneration of the ST and G tendons. The low NPV also indicates that inspection can provide us with a large number of false-negative results.

Despite the alleged regenerative capacity of the hamstring tendons, the clinical significance of this finding as well as the biomechanical characteristics of the new tendons remain unclear. ${ }^{14-16}$ Studies evaluating the correlation between the regeneration of ST and G tendons and the recovery of knee flexor muscle strength have been published recently. In 2012, Choi et al., evaluated 45 patients using isokinetic tests and found a direct relationship between knee flexor strength and the degree of regeneration of the flexor tendons. ${ }^{17}$ Furthermore, the number of regenerated tendons (both or only one) had a direct correlation with the knee flexor force measured by isokinetic testing. These authors considered that the technique used for graft removal might display a significant correlation with the rate of regeneration. In our clinical setting, the data described herein are relevant as harvesting of homologous grafts necessary for the treatment of multi-ligament knee injuries and revision surgeries, where contralateral hamstrings are not available and other tendons are not of sufficient length for satisfactory reconstruction, is difficult. Nevertheless,

Table 5. Comparison of visual inspection and magnetic resonance imaging (MRI) findings for the evaluation of semitendinosus and/or gracilis tendon regeneration.

\begin{tabular}{l|c|c|c|c}
\hline \multicolumn{2}{c|}{ Yes } & \multicolumn{3}{c}{ MRI } \\
\cline { 3 - 5 } \multicolumn{2}{c|}{} & No & Total & \\
\hline \multirow{3}{*}{ Visualization } & Yes & 11 & 0 & 11 \\
\cline { 2 - 5 } & No & 14 & 5 & 19 \\
\cline { 2 - 5 } & Total & 25 & 5 & 30 \\
\hline
\end{tabular}


this study has limitations, with the number of participants ( $\mathrm{n}=$ 30) examined being the most important. Obviously, an extension of the follow-up period would eventually allow the aggregation of cases in the group that obtained tendon regeneration, without interfering with the outcome results. Clinical parameters (strength, range of motion, flexibility, and functional scores) were not taken into consideration in this study, as the aim was to observe tendon regeneration and not surgical outcome.

\section{CONCLUSION}

Partial or total regeneration of ST and $\mathrm{G}$ tendons was evaluated with $M R I$ in patients who underwent $A C L$ reconstruction using autografts of these tendons. Palpation on physical examination was effective to evaluate the regeneration of ST and G tendons. Our study showed that MRI was the most reliable method to evaluate ST and $\mathrm{G}$ tendon regeneration. Over the time interval studied, only a fraction of patients presented complete regeneration of the ST and $\mathrm{G}$ tendons.

\section{ACKNOWLEDGMENTS}

The authors gratefully acknowledge the contribution of Dr. Ricardo Dizioli Navarro (in memoriam), for his long-standing contributions to this work, beyond his contribution to the training of researchers involved.

AUTHORS' CONTRIBUTIONS: Each author contributed individually and significantly to the drafting of the manuscript. LJBA (0000-0002-0400-3685)* and $\mathrm{PD}(0000-0003-3592-6981)^{*}$ were the main contributors to the drafting of the manuscript. CESF (0000-0002-0932-6870)*, JVN (0000-0002-8168-3469)*,GMG (0000-0003-0601-0712)* and MVML (0000-0003-1345-6915)* performed surgery, followed the patients, and gathered clinical data. JVN, and PD performed the statistical analysis. PD, GM), MVML and LJBA performed bibliographic research, reviewed the manuscript, and contributed to the study's intellectual concept. *ORCID (Open Researcher and Contributor ID).

\section{REFERENCES}

1. Macleod TD, Snyder-Mackler L, Axe MJ, Buchanan TS. Early regeneration determines long-term graft site morphology and function after reconstruction of the anterior cruciate ligament with semitendinosus-gracilis autograft: a case series. Int J Sports Phys Ther. 2013;8(3):256-68.

2. Simonian PT, Harrison SD, Cooley VJ, Escabedo EM, Deneka DA, Larson RV. Assessment of morbidity of Semitendinosus and gracilis tendon harvest for $\mathrm{ACL}$ Reconstruction. Am J Knee Surg. 1997;10(2):54-9.

3. Eriksson K, Hamberg P, Jansson E, Larsson H, Shalabi A, Wredmark T. Semtendinosus muscle in anterior cruciate ligament surgery: Morphology and function. Arthroscopy. 2001;17(8):808-17.

4. Stevanović V, Blagojević Z, Petković A, Glišić M, Sopta J, NikolićV, et al. Semitendinosus tendon regeneration after anterior cruciateligament reconstruction: can we use it twice? Int Orthop. 2013;37(12):2475-81.

5. Yoshiya S, Matsui N, Matsumoto A, Kuroda R, Lee S, Kurosaka M. Revision Anterior Cruciate Ligament Reconstruction Using the Regenerated Semitendinosus Tendon: Analysis of Ultrastructure of the Regenerated Tendon. Arthroscopy. 2004;20(5):532-5.

6. Cross MJ, Roger G, Kujawa P, Anderson IF. Regeneration of the semitendinosus and gracilis tendons following their transection for repair of the anterior cruciate ligament. Am J Sports Med. 1992;20(2):221-3.

7. Morelli F, Ferretti A, Conteduca F, Masi V. Histological assessment of regeneration of the semitendinosus tendon following its use for ACL reconstruction. J Sport Traumatol Relat Res. 2000;22(2):65-9.

8. Eriksson K, Kindblom LG, Hamberg P, Larsson H, Wredmark T. The semitendinosus tendon regenerates after resection, a morphologic and MRI analysis in 6 patients after resection for anterior cruciate ligament reconstruction. Acta Orthop Scand. 2001;72(4):379-84.

9. Papandrea P, Vulpiani MC, Ferreti A, Conteduca F. Regeneration of the semitendinosus tendon harvested for ACL Reconstruction: Evaluation using ultrasonography. Am J Sports Med. 2000;28(4):556-61.

10. Tabuchi K, Soejima T, Murakami H, Noguchi K, Shiba N, Nagata K. Inducement of tissue regeneration of harvested hamstring tendons in a rabbit model. Bone Joint Res. 2016;5(6):247-52.

11. Rispoli DM, Sanders TG, Miller MD, Morrison WB. Magnetic resonance imaging at different time periods following hamstring harvest for anterior cruciate ligament reconstruction. Arthroscopy. 2001;17(1):2-8.

12. Zaccherotti G, Olmastroni M, Battaglini M. Semitendinosus and gracilis tendon regeneration after harvesting for ACL Reconstruction. In: 2001 ISAKOS Congress, Montreux, Switzerland, $14^{\text {th }}-18^{\text {th }}$, may, 2001. Paper Abstracts. Montreux, Switzerland, 2001. (Paper 75).

13. Suijkerbuijk MA, Reijman M, Lodewijks SJ, Punt J, Meuffels DE. Hamstring Tendon Regeneration After Harvesting: A Systematic Review. Am J Sports Med. 2015;43(10):2591-8.

14. Papalia R, Franceschi F, D'Adamio S, Diaz Balzani L, Maffulli N, Denaro V. Hamstring Tendon Regeneration After Harvest for Anterior Cruciate Ligament Reconstruction: A Systematic Review. Arthroscopy. 2015;31(6):1169-83.

15. Murakami H, Soejima T, Inoue T, Kanazawa T, Noguchi K, Katouda M, et al. Inducement of semitendinosus tendon regeneration to the pes anserinus after its harvest for anterior cruciate ligament reconstruction-A new inducer grafting technique. Sports Med Arthrosc Rehabil Ther Technol. 2012;4(1):17.

16. Lubowitz JH. Editorial Commentary: Hamstring Tendon Regeneration After Autograft Harvest. Arthroscopy. 2015;31(6):1184.

17. Choi JY, Ha JK, Kim YW, Shim JC, Yang SJ, Kim JG. Relationships Among Tendon Regeneration on MRI, Flexor Strength, and Functional Performance After Anterior Cruciate Ligament Reconstruction With Hamstring Autograft. Am J Sports Med. 2012;40(1):152-62. 